International Journal of

BioScience and Applications

\title{
Nursing Students' Experiences of Participating in the Learning Community in COVID-19 Pandemic
}

\author{
Nan Young Song ${ }^{1}$, Suhyun Kim ${ }^{2 *}$ \\ ${ }^{1}$ Doctoral Student, Department of Nursing, Nambu University, 23 Ceomdanjungang-ro, Gwangsan-gu, Gwangju, \\ 62271, Public of Korea \\ ${ }^{2}$ Assistant Professor, Department of Nursing, Nambu University, 23 Ceomdanjungang-ro, Gwangsan-gu, \\ Gwangju, 62271, Public of Korea
}

\begin{abstract}
Background/Objectives: This study is a qualitative study that attempted to explore the experiences of nursing students participating in the learning community in the COVID-19 situation through the content analysis method. Methods/Statistical analysis: Data collection was conducted for 10 nursing students in 2021 The data analysis of this study was analyzed using content analysis based on the recorded data of the in-depth interview and the transcribed data. Findings: Four categories and eighteen sub-area themes were derived from the research question. Students' online learning community activities were classified into the stages of planning, implementation, evaluation, and reflection. Improvements/Applications: In the future, it is necessary to develop the online learning community program based on active interaction and verifying the effectiveness
\end{abstract}

\section{Index Terms}

Nursing Students, Learning Community, COVID-19, Qualitative Research, Content Analysis

\section{Corresponding author : Suhyun Kim}

ksh136112@nambu.ac.kr

- Manuscript received July 15, 2021.

- Revised August 10, 2021 ; Accepted September 1, 2021

- Date of publication September 30, 2021

(C) The Academic Society of Convergence Science Inc.

2619-8363 @ 2021 IJBSA. Personal use is permitted, but republication/redistribution requires IJBSA permission. 


\section{INTRODUCTION}

Higher education has also undergone many changes due to the COVID-19 pandemic [1]. One of them is that, as online learning expands, instructors and learners interact in online learning activities [13]. In addition, in higher education, attempts are being made for college students to form collaborative knowledge online [4, 5].

An online learning community is a cooperative learning system in which learning takes place in an online space where people can interact with each other [6]. In other words, people with common learning goals gather to discuss topics, share data, and produce knowledge in order to achieve their goals [7]. In this way, a cooperative learning environment that constructs and internalizes knowledge online provides an opportunity for individual learners and communities to grow together [8]. Learning community induces active and active learning rather than memorization learning and enables in-depth learning [6-8].

Because effective teaching begins with understanding the target audience, it is very important to understand the students who are experiencing changes in education and learning styles that they have not experienced before in the context of the COVID-19 pandemic [9]. Therefore, exploring the learning experience of the online learning community in the context of the COVID-19 infectious disease can provide a direction for understanding learners and in-depth learning in future education. So far, studies have been conducted on the effectiveness of the learning community program. $[6,10,11]$. In order to find strategies for more effective operation, it is necessary to understand learners' experiences as a learnercentered approach.

Therefore, this study aims to explore the experiences of nursing students participating in the learning community through content analysis in the context of COVID-19. The content analysis method is a research method that classifies unstructured data using a type-specific system and infers conclusions through careful interpretation [12]. This is a method of extracting and analyzing the information necessary to obtain an answer to a research project based on the information base contained in the text, which is the raw material [13]. In other words, this study intends to use the content analysis method to analyze the information necessary to find an answer to what nursing students' experiences of participating in the learning community were.

\section{MATERIALS AND METHOD}

\section{A. Study Design}

This study is a qualitative study that attempted to explore the experiences of nursing students participating in the learning community in the COVID-19 situation through the content analysis method.

\section{B. Participants}

The subjects of this study were 10 third-year students of the Department of Nursing at the University of Nursing in $G$ city in Korea. The purpose sampling method was used to recruit subjects suitable for the purpose of the study. Objective sampling is a method of expressing as a sample the subjects judged to be able to represent the population well according to the subjective judgment of the researcher [14].

\section{Data Collection}

Data collection was conducted from March to June 2021, and recruitment was announced through the bulletin board of the university in $\mathrm{G}$ city in Korea. This researcher conducted an in-depth interview with 10 nursing college students who voluntarily applied for participation through a recruitment notice. The in-depth interview took about 50-90 minutes.

\section{Data Analysis}

The data analysis of this study was analyzed using content analysis based on the recorded data of the indepth interview and the transcribed data. First, meaningful words, sentences, and paragraphs were extracted while the researcher read the transcribed material repeatedly. When extracting meaningful words, the researcher carefully looked at the context of the data and the participants' reactions. Then, based on the previous research, the learning experiences were classified according to the stage, and the data corresponding to each category was named and classified. In order to secure the validity of the research results, the researchers reviewed each other and provided feedback.

\section{E. Study Validity and Rigor}

In this study, efforts were made to increase the rigor of qualitative research according to the four criteria suggested by Lincoln and Guba [15]. To secure the first reliability, this researcher recorded all interview contents during the research process, transcribed them as they are, analyzed them, and checked whether the descriptions of the experiences were clearly analyzed by the 5 participants who participated in the study. To secure the second suitability, after the participants' learning community activities were completed, the contents recorded through the diaries of the participants' experiences 
and the analytic memos of the researchers were read and analyzed several times. In addition, it was checked whether the experiences with the study participants were consistent with other students who did not participate in the study. Third, for auditability, an explanation of the data collection process, data analysis process, and submitted results were described, and the analysis was carried out after confirming with fellow researchers. Fourth, for the sake of corroboration, we tried to derive the research results neutrally by excluding the researchers' prejudice and reflecting and evaluating the interim evaluation of the study participants' operation of the learning community. This study satisfies corroboration by securing the reliability, suitability, and auditability of the study.

\section{F. Ethical Considerations}

The researcher posted the recruitment notice on an online bulletin board mainly used by nursing students. Students interested in participating in the research were asked to leave a personal message to the researcher and voluntarily express their intention to participate. The purpose of the research, research methods, data collection, confidentiality, and guarantee of anonymity were explained to the research participants so that they could voluntarily participate in the research. The researcher explained to the study participants that they could withdraw from the study at any time during the study, and that this did not affect the individual evaluation score. Only those who understood the purpose of this study and voluntarily consented to participate in the study were interviewed after obtaining a written consent form.

\section{RESUlt AND DiscuSSION}

This study was attempted to explore the experiences of nursing students participating in the learning community in the context of the COVID-19 infectious disease. Through this, it is intended to seek the direction of qualitative improvement and operation of nursing students' proactive and active learning community program and to prepare a plan to maximize its effect. Four categories and eighteen sub-area themes were derived from the research question. The results are as follow. Students' online learning community activities were classified into the stages of planning, implementation, evaluation, and reflection. These were analyzed based on the conceptual model of Zuber-Skerritt and Fletcher [16] (Figure 1).

An example of an online learning community activity plan is shown in Table 1. Participants operated a learning community through zoom for 2 hours each for 6 weeks. We created an SNS channel for the activities of the learning community and shared the results of the activities. An example of posting online learning community activities on SNS is shown in Figure 2. The detailed content analysis results are shown in Table 2.

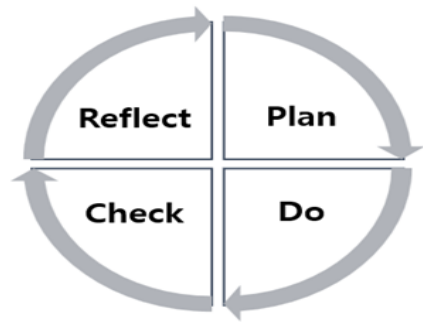

Fig. 1. Conceptual model

Table 1. The eXample of Learning Community Plan

\begin{tabular}{|c|c|c|c|c|}
\hline $\begin{array}{l}\text { Learning } \\
\text { topic }\end{array}$ & \multicolumn{4}{|c|}{$\begin{array}{l}\text { Making a summary note based on the review of } \\
\text { Women's Health Nursing }\end{array}$} \\
\hline $\begin{array}{l}\text { Learning } \\
\text { Objectives }\end{array}$ & \multicolumn{4}{|c|}{$\begin{array}{l}\text { - Accurately understand the contents of women's } \\
\text { health nursing studies. } \\
\text {-Schematize your knowledge through summary } \\
\text { notes. } \\
\text {-Spread the knowledge by sharing knowledge } \\
\text { related to women's health with nursing students } \\
\text { and general women through SNS }\end{array}$} \\
\hline $\begin{array}{l}\text { Ground } \\
\text { rules }\end{array}$ & \multicolumn{4}{|c|}{$\begin{array}{l}\square \text { Create summary notes } \\
\square \text { Organize your learning } \\
\square \text { Prepare the preparations for the schematic } \\
\square \text { to be actively involved } \\
\square \text { If you're late for the deadline, buy coffee for } \\
\text { your co-workers. } \\
\square \text { If you do not actively participate, you will be } \\
\text { fined } 1,000 \text { won. }\end{array}$} \\
\hline Category & Week & Place & $\begin{array}{l}\text { Action } \\
\text { Method }\end{array}$ & Topic \& contents \\
\hline \multirow{3}{*}{$\begin{array}{c}\text { Action } \\
\text { plan }\end{array}$} & 1 & zoom & $\begin{array}{c}\text { Summary } \\
\text { note } \\
\& \text { SNS }\end{array}$ & $\begin{array}{l}\text { Reviewing the } \\
\text { fertilization } \\
\text { process and } \\
\text { fetal } \\
\text { development, } \\
\text { Overall } \\
\text { summary, } \\
\text { SNS sharing }\end{array}$ \\
\hline & 2 & zoom & $\begin{array}{c}\text { Summary } \\
\text { note } \\
\& \text { SNS }\end{array}$ & $\begin{array}{l}\text { Review of } \\
\text { assessment of } \\
\text { fetal health } \\
\text { Overall } \\
\text { summary, } \\
\text { SNS sharing }\end{array}$ \\
\hline & 3 & zoom & $\begin{array}{c}\text { Summary } \\
\text { note } \\
\& \text { SNS }\end{array}$ & $\begin{array}{l}\text { physiological } \\
\text { changes in } \\
\text { pregnant } \\
\text { women, } \\
\text { according to } \\
\text { physiological } \\
\text { changes } \\
\text { Recognize } \\
\text { signs and } \\
\text { symptoms of } \\
\text { pregnancy, } \\
\text { Overall } \\
\text { summary, } \\
\text { SNS sharing }\end{array}$ \\
\hline
\end{tabular}



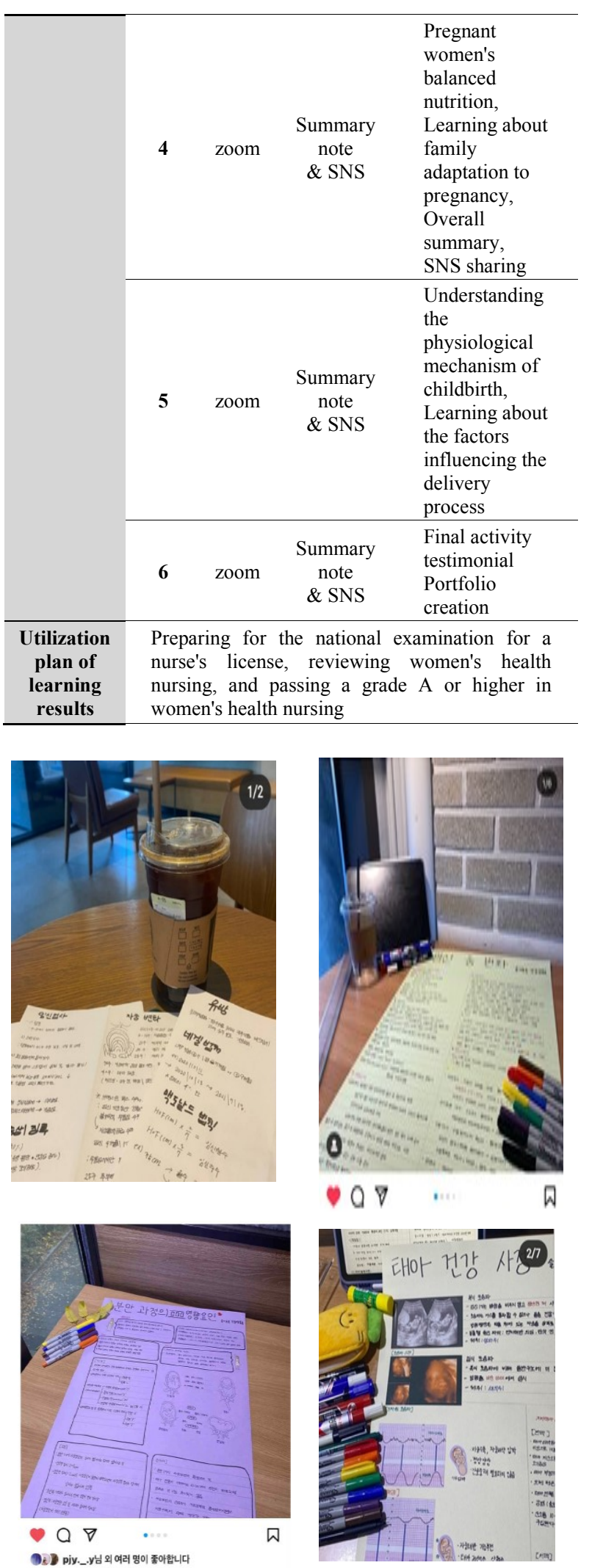

Fig. 2. The activity examples of Instargram

Participants performed learning community activities according to the following four steps. The results of analyzing the contents according to the activity contents of each stage are as follows.

\section{A. Plan stage}

a. Recruiting team members for the purpose of developing competency

"Since we are in our 3rd year now, we wanted to develop not only credit management, but also our competency as a pre-nursing nurse. I have recruited team members who have the same thoughts as me."

b. Select the subject of the subject currently studying

"I thought about what subjects we could focus on. I thought I should be learning during the semester now. That's why we selected it as a course in Women's Health Nursing."

c. Plan learning community activities that can be done in the context of COVID-19

"Social distancing has been strengthened due to COVID-19. We couldn't meet, but we had to create an atmosphere where we could learn. Then, you need to operate a learning community through online activities. What activities are there? - I worried a lot."

d.. Establish ground rules that can be consistently practiced

"We recruited team members, but we felt we needed rules to achieve our goals. We set up an environment where we could keep our promises by setting our own rules and imposing penalties."

e. Set achievable goals

"We set goals. We thought of a goal that could be achieved without being overbearing and having fun." f. Selected online platform

"I was thinking about whether to select Teams program, Zoom, or Kakao face talk program for online activities. Last year, I decided to use zoom, which was used a lot in class. I thought that online access through zoom could record activities comfortably and the connection status was stable."

\section{B. Do stage}

\section{a. Participate in online meetings through Zoom}

"We had regular meetings every week through Zoom at a set time. At first, I was confused as to how to proceed. But gradually I got used to online meetings."

\section{b. Summarize and share what you have learned}

"I summarized what I learned in class and what I learned on my own and explained it to my friends. Sharing what I have learned is an experience that I 
pass on to my colleagues like a professor."

c. Schematic of the summary

"Our activities include not only writing, but also drawing and pasting pictures. I think it's interesting to co-workers to have a nice schematization of what we've learned."

d. Take a picture of the schematic and share it on social media

"I took pictures of what I learned and schematized and recorded it. And I shared it on instagram. I felt a sense of responsibility not only for myself but also for sharing learning activities around me."

\section{Check stage}

a. Check the "Likes" of Followers through Instagram.

"Through Instagram, the reactions of my followers have been encouraging. My followers liked my photos and left comments. We were able to interact online and make learning fun."

b. See myself and colleagues who practice consistently

"We planned an activity for 6 weeks and performed every activity every week. We were proud of ourselves and our colleagues."

c. Check the execution of the process according to the plan

"Establishing an activity plan and checking it while implementing the plan also boosted my learning ability. The experience of setting goals and working together can be applied to other studies as well."

d. Received comments from the professor on the mid-term evaluation

"We showed our activities to the professor in charge of Women's Health Nursing. We brag about our activities and check the level of learning. Having confirmation that we were doing well gave us confidence in our learning activities."

\section{Reflect stage}

\section{a. Achievement of small goals and the feeling of pride}

"It's our only activity, but it feels great to have achieved a small goal."

b. Successfully completed the learning community activity because of the presence of colleagues

"I had a successful learning community activity with my colleagues. I realized the importance of cooperative learning." c. Gaining strength through encouragement and support through social media

"By receiving a lot of encouragement and support through social media, we have gained the strength to continue working hard in the future."

\section{d. Have fun through active learning}

"We enjoyed the whole itinerary as a tour. We felt ourselves growing as we made plans and put them into action. I want to actively study other subjects like this."

Participants had a self-directed learning experience through four stages of activity, and felt fun through active learning. This learning-led experience gave the participants confidence and made them plan to expand to other subjects.

\section{Table 2. Content Analysis}

\begin{tabular}{|c|c|}
\hline Category & Subcategory \\
\hline Plan & $\begin{array}{l}\text {-Recruiting team members for the purpose of } \\
\text { developing competency } \\
\text {-Select the subject of the subject currently } \\
\text { studying } \\
\text {-Plan learning community activities that can } \\
\text { be done in the context of COVID-19 } \\
\text {-Establish ground rules that can be } \\
\text { consistently practiced } \\
\text {-Set achievable goals } \\
\text {-Selected online platform }\end{array}$ \\
\hline Do & $\begin{array}{l}\text {-Participate in online meetings through Zoom } \\
\text {-Summarize and share what you have learned } \\
\text {-Schematic of the summary } \\
\text {-Take a picture of the schematic and share it } \\
\text { on social media }\end{array}$ \\
\hline Check & $\begin{array}{l}\text {-Check the "Likes" of Followers through } \\
\text { Instagram. } \\
\text {-See myself and colleagues who practice } \\
\text { consistently } \\
\text {-Check the execution of the process } \\
\text { according to the plan } \\
\text {-Received comments from the professor on } \\
\text { the mid-term evaluation }\end{array}$ \\
\hline Reflect & $\begin{array}{l}\text {-Achievement of small goals and the feeling } \\
\text { of pride } \\
\text {-Successfully completed the learning } \\
\text { community activity due to colleagues } \\
\text {-Gaining strength through encouragement } \\
\text { and support through social media } \\
\text {-Have fun through active learning }\end{array}$ \\
\hline
\end{tabular}

In the content analysis of this study, it was shown that the learning community activities were successfully completed due to peers, and this is also shown in previous studies that the learning community program enhances the cooperative learning capacity [11]. This means that online-based 
learning community activities in the context of COVID-19 are as effective as offline to enhance cooperative learning capabilities. In the future, it is necessary to find a strategy to increase the interaction of the online learning community and help promote cooperative learning of students.

In this study, students were active through Zoom, but a learning community can also be formed through online cafes [17]. Learning community activities through the online cafe centered on physical education teachers also contributed to class improvement and positive ties. appeared to be However, compared with previous studies, it is thought that these negative aspects did not appear because the participants of this study were college students and had no experience of participating in an offline learning community.

There is also a case of using the virtual conversation series as a precedent study on the activities of a learning club that appeared newly in the Corona 19 situation [4]. The learning community of the virtual consensus series was run by residents and clinicians working on the front lines of COVID19 participating in a 40-minute discussion with medical students via Zoom [4]. At this time, the evaluated learning satisfaction was found to be very good. In another study, there is a case of operating a virtual learning community for the purpose of wellbeing [18]. During the COVID-19 pandemic, the Virtual Wellness and Learning Communities (VWLC) program was operated for medical students whose psychological and mental health as well as learning community activities are weakened due to social distancing [18]. For some people, sense of connectivity with peers decreased due to COVID-19, and it was confirmed that sense of connectivity with peers increased through the program [18]. However, some people did not participate in the program due to unfamiliarity with attendees and screen fatigue [18].

\section{Conclusion}

This study was attempted to examine the utilization plan as a future teaching method by exploring the online learning community activity experiences of nursing students through the content analysis method and to seek strategies to increase the students' learning effect.

Through this study, it was possible to explore the online learning community activity experiences of nursing students, and these results will serve as basic data for developing an online learning community based on active interaction and verifying the effectiveness in the future. In addition, this study served as an opportunity to confirm that sharing learning outcomes through SNS can lead to unintended learning effects. Since this study was conducted with students from one region, there is a limitation in generalization.

\section{ACKNOWLEDGMENT}

The study's authors would like to express their heartfelt appreciation to the study participants. This study would not have been possible without their valuable time and support.

\section{REFERENCES}

[1] Deery, C. (2020). The COVID-19 pandemic: implications for dental education. Evid Based Dent, 21(2), 46-47. doi:10.1038/s41432-020-0089-3

[2] Christopher, R., de Tantillo, L., \& Watson, J. (2020). Academic caring pedagogy, presence, and Communitas in nursing education during the COVID-19 pandemic. Nurs

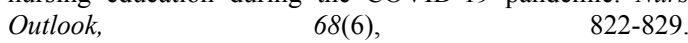
https://doi.org/10.1016/j.outlook.2020.08.006

[3] Wu, D. T., Wu, K. Y., Nguyen, T. T., \& Tran, S. D. (2020). The impact of COVID-19 on dental education in North America-Where do we go next? Eur J Dent Educ, 24(4), 825-827. https://doi.org/10.1111/eje.12561

[4] Anderi, E., Sherman, L., Saymuah, S., Ayers, E., \& Kromrei, H. T. (2020). Learning Communities Engage Medical Students: A COVID-19 Virtual Conversation Series. Cureus, 12(8), e9593. https://doi.org/10.7759/cureus.9593

[5] Solá, O., \& Marquez, C. (2020). Integrating Social Determinants of Health Into Clinical Training During the COVID-19 Pandemic. PRIMER, 4, 28. https://doi.org/10.22454/PRiMER.2020.449390

[6] Rhim, H. C., \& Han, H. (2020). Teaching online: foundational concepts of online learning and practical guidelines. Korean $J$ Med Educ, 32(3), 175-183. https://doi.org/10.3946/kjme.2020.171

[7] Griffiths, J. (2020). E-learning, during the pandemic and beyond. $\mathrm{Br} J$ Community Nurs, 25(6), 265. https://doi.org/10.12968/bjcn.2020.25.6.265

[8] Tilley, D. S., Boswell, C., \& Cannon, S. (2006). Developing and establishing online student learning communities. Comput Inform Nurs, 24(3), 144-149; quiz 150-141. https://doi.org/10.1097/00024665-200605000-00010

[9] Waddington, A. M., \& Porter, S. D. (2021). Developing social presence in online learning among nurses: Exploration of the community of inquiry models domain of social using a qualitative descriptive design. Nurse Educ Pract, 52, 103000. https://doi.org/10.1016/j.nepr.2021.103000

[10] Jumaat, N. F., \& Tasir, Z. (2014). Instructional scaffolding in online learning environment: A meta-analysis. Paper presented at the 2014 international conference on teaching and learning in computing and engineering.

[11] Cho, B.-R. (2020). The Effect of Learning Community Program Participation on College Students' Communication Skills and Cooperative Learning Competency. Journal of Digital Convergence, 18(5), 43-54.

[12] Krippendorff, K. (2018). Content analysis: An introduction to its methodology: Sage publications.

[13] Choi, S., Jung, J., \& Jung, S. (2016). Concept and procedures of qualitative content analysis. Journal of Qualitative Inquiry, 2(1), 127-155.

[14] Schreier, M. (2018). Sampling and generalization. The SAGE handbook of qualitative data collection, 84-97.

[15] Guba, E. G., \& Lincoln, Y. S. (1981). Effective evaluation: Improving the usefulness of evaluation results through responsive and naturalistic approaches: Jossey-Bass.

[16] Zuber Skerritt, O., \& Fletcher, M. (2007). The quality of an action research thesis in the social sciences. Quality Assurance in Education 
[17] Yoon, K., Lee, G., \& Lee, C. (2018). A case study of using an online cafe in a physical education teacher learning community. Korean Journal of Sport Pedagogy, 25(4), 2140. https://doi.org/10.21812/kjsp.2018.10.25.4.21

[18] Ahlers, C. G., Lawson, V., Lee, J., March, C., Schultz, J., Anderson, K., ... . Drolet, B. C. (2021). A Virtual Wellness and Learning Communities Program for Medical Students during the COVID-19 Pandemic. South Med J, 114(12), 807811. https://doi.org/10.14423/smj.0000000000001330 